\title{
Fetal Distress
}

National Cancer Institute

\section{Source}

National Cancer Institute. Fetal Distress. NCI Thesaurus. Code C50563.

Signs or symptoms which may be indicative of distress to a fetus, which may include repetitive variable decelerations, fetal tachycardia or bradycardia, late decelerations, or low biophysical profile. 